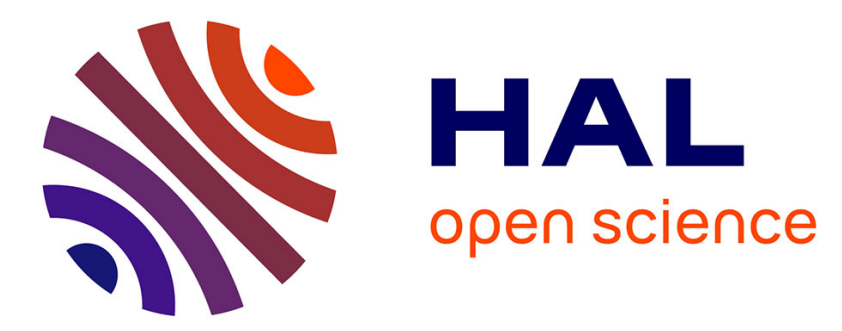

\title{
Eco-friendly direct (hetero)-arylation polymerization: scope and limitation
}

Simiao Yu, Fuchuan Liu, Jianwei Yu, Shiming Zhang, Clément Cabanetos, Yongqian Gao, Wei Huang

\section{To cite this version:}

Simiao Yu, Fuchuan Liu, Jianwei Yu, Shiming Zhang, Clément Cabanetos, et al.. Eco-friendly direct (hetero)-arylation polymerization: scope and limitation. Journal of Materials Chemistry C, 2017, 5 (1), pp.29-40. 10.1039/C6TC04240F . hal-02564163

\section{HAL Id: hal-02564163 \\ https://univ-angers.hal.science/hal-02564163}

Submitted on 20 Sep 2021

HAL is a multi-disciplinary open access archive for the deposit and dissemination of scientific research documents, whether they are published or not. The documents may come from teaching and research institutions in France or abroad, or from public or private research centers.
L'archive ouverte pluridisciplinaire HAL, est destinée au dépôt et à la diffusion de documents scientifiques de niveau recherche, publiés ou non, émanant des établissements d'enseignement et de recherche français ou étrangers, des laboratoires publics ou privés. 


\title{
Eco-friendly direct (hetero)-arylation polymerization: scope and limitation
}

\author{
Simiao Yu, ${ }^{a}$ Fuchuan Liu, ${ }^{a}$ Jianwei $\mathrm{Yu}^{\mathrm{a}}$ Shiming Zhang, ${ }^{* a}$ Clement Cabanetos, ${ }^{\text {b }}$ \\ Yongqian $\mathrm{Gao}^{\mathrm{a}}$ and Wei Huang ${ }^{\star a}$ \\ ${ }^{a}$ Key Laboratory of Flexible Electronics (KLOFE) \& Institute of Advanced Materials \\ (IAM), Jiangsu National Synergetic Innovation Center for Advanced Materials \\ (SICAM), Nanjing Tech University (NanjingTech), 30 South Puzhu Road, \\ Nanjing 211816, China. E-mail: iamsmzhang@njtech.edu.cn \\ ${ }^{b}$ CNRS UMR 6200, MOLTECH-Anjou, University of Angers, 2 Bd Lavoisier, \\ 49045 Angers, France
}

Polymer semiconductors have recently attracted considerable attention owing to their (i) excellent optical properties, (ii) processability, (iii) inherent tunability of the energetics, and (iv) synthetic versatility. Consequently, researchers have shown great interest in developing ecofriendly polymerization methods to reduce the synthetic cost of such macromolecular materials, including the so-called direct (hetero)arylation polymerization (DHAP). In addition to reducing the number of synthetic steps, required in conventional cross-coupling polymerizations, DHAP avoids the use of lithiated and/or stannylated intermediates that are highly toxic and/or dangerous. In this contribution, we reviewed a number of conjugated polymers prepared by DHAP for applications in organic electronics, and more precisely for organic photovoltaics and field-effect transistors. Moreover, emphasis has been put on polymerization reaction conditions (i.e., the nature of the catalysts, ligands and solvents) and their impact on the properties of the material. Even though some optimizations still remain, regarding the current trends, it is obvious that DHAP will play a larger role in the design and synthesis of polymer semiconductors.

\section{Introduction}

Transition-metal-catalyzed $\mathrm{C}-\mathrm{C}$ coupling reactions have been, and continue to be, some of the most principal reactions in organic chemistry, widely applied to the synthesis of natural products, pharmaceutical intermediates or even organic functional materials. Until recently, traditional cross-coupling reactions, namely, Suzuki-Miyaura, Stille, Negishi, Sonogashira and Kumada, have been the primary means of forming carboncarbon (C-C) bonds. ${ }^{1-3}$ However, these methods typically involve halogenated and organometallic reagents, thus generating stoichiometric amounts of undesirable and toxic by-products. Moreover, additional synthetic steps, including group-protection and/or activation of aromatic rings, are required to prepare these intermediates. It is noteworthy that such synthetic and environmental problems have plagued researchers for a long time. ${ }^{4}$ Furthermore, within the current context of the increasing demand for atomic economy reactions and green chemistry, ${ }^{5}$ researchers have more recently focused their efforts on the exploration of new cross-coupling methods.

Considering that the carbon-hydrogen $(\mathrm{C}-\mathrm{H})$ bond is one of the most common chemical bonds among organic compounds, the formation of a $\mathrm{C}-\mathrm{C}$ bond by coupling an aromatic hydrogen activated compound directly to a halogenated aromatic reagent would provide a powerful tool to fulfill the atomic economy requirement since the only by-product generated within the media is a hydrogen halide $(\mathrm{H}-\mathrm{X}){ }^{6}$ This synthetic method, called direct (hetero)-arylation (DHA), has shown great potential over the last few years in synthesizing compounds without organometallic reagents (such as Grignard reagents, organozinc or organotin). ${ }^{7}$ Additionally, this method is not only a good way to resolve problems inherent within traditional cross-coupling reactions but also a particularly appealing strategy for generating $\mathrm{C}-\mathrm{C}$ bonds as well as $\mathrm{C}-\mathrm{X}$ bonds. ${ }^{8}$ Many researchers have been eyeing this emerging field in recent decades. In 2002, Lemaire et $a{ }^{1}{ }^{1}$ summarized the results obtained in the field of aryl-aryl bond formation using various kinds of reactions and technologies. To some extent they drew a relatively complete picture of the current efforts in this area. More recently, Leclerc and fellow researchers ${ }^{8}$ systematically and comprehensively summed up the present studies on direct (hetero)-arylation polymerization (DHAP). They discussed general and adaptable reaction conditions for the synthesis of defect-free as well as high-molecular-weight conjugated polymers; a discussion which constructed a bright outlook about the field.

Thus, DHA represents an efficient strategy for the preparation of a large number of aromatic blocks or monomers. Particularly, it offers a highly valuable and economical synthetic method for large-scale production, and commercially viable preparations of various compounds for organic electronics ${ }^{4}$ including applications such as organic photovoltaics (OPV), ${ }^{9-13}$ organic field-effect transistors (OFET) ${ }^{14-19}$ and/or organic light-emitting diodes (OLED); ${ }^{20,21}$ for instance, polymer solar cells (PSCs) and polymer photovoltaic materials have benefited from significant and remarkable advances over the last decades. ${ }^{22}$ New photovoltaic materials (donors and acceptors) and device structures are reported with each passing day, and peak power conversion efficiency (PCE) is regularly being increased. ${ }^{23-26}$

As a C-H activation method, DHAP can simplify and shorten the synthetic process, minimize the presence of difficult-toremove by-products, and at the same time afford new compounds that can be achieved with relatively less cost. ${ }^{27}$ Consequently, this method will undoubtedly contribute in removing technological and practical barriers. In this context, the aim of this review is to summarize selected examples of conjugated polymers prepared via DHAP and to discuss the added value, scope and limitation inherent in this method with a particular focus on the structureproperty relationships. 


\section{Comparison with traditional cross- coupling reactions}

Recently, DHAP has emerged to provide efficient access to new conjugated macromolecular materials. Since then, a significant amount of effort has gone into developing, refining, and popularizing this new method. Indeed, among its advantages recent literature has reported DHAP as a cheap and atomeconomical tool when compared to conventional organometallic cross-coupling reactions. ${ }^{28-31}$

Allard $e t a .^{32}$ described for the first time the preparation of thieno[3,4- $d]$ thiazole-based (TTz) alternating copolymers synthesized via Stille, Suzuki or DHAP methods (Scheme 1). First, polymer P1-1 was synthesized via conventional Stille crosscoupling between 2-octylthieno[3,4- $d]$ thiazole and 2,6-dibromo4,8-di(ethylhexyl-oxyl)benzo[1,2-b:4,5- $\left.b^{\prime}\right]$ dithiophene (BDT) and compared to its analogous P1-2 synthesized via DHAP. Both polymers showed a comparable molecular weight $\left(M_{\mathrm{n}}\right)$ of $c a$. $32 \mathrm{kDa}^{33}$ demonstrating that direct arylation is a possible method to obtain $M_{\mathrm{n}}$ as high as those achieved by conventional coupling reactions.

In parallel, both polymer $\mathbf{P 2}$ and polymer $\mathbf{P 3}$ were synthesized via DHAP (Scheme 2). For P2, 5-(2-ethylhexyl)thieno[3,4c]pyrrole-4,6-dione (TPD) was coupled with 4,6-dibromo-2octylthieno[3,4- $d]$ thiazole. A low molecular weight of $8 \mathrm{kDa}$ was determined and was correlated with the strong rigidity of the polymer backbone resulting from the interaction between the thiophene ring of the TTz unit and the ketone borne by the TPD unit, resulting in the reduction of the solubility of this material. ${ }^{34}$ However, it turns out that DHAP is probably the only available method to afford this polymer. Indeed, all attempts performed in conventional conditions failed. Polymer P3 has also been synthesized under the same conditions used for $\mathbf{P} 2$ by polymerizing the 3,6-bis(5-bromothiophen-2-yl)-2,5-bis(2-octyldodecyl)pyrrolo-[3,4-c]pyrrole-1,4(2H,5H)-dione and 2-octylthieno$[3,4-d]$ thiazole monomers. In this case, a molecular weight of $c a$. $17 \mathrm{kDa}$ was measured. It is noteworthy that $\mathbf{P} 3$ could also be prepared via Suzuki coupling since diketopyrrolopyrrole (DPP) units bearing pinacol borane groups have already been reported. ${ }^{35}$ However, the synthesis cost of $\mathbf{P} \mathbf{3}$ via Suzuki coupling is quite high, which leads to DHAP being the method of choice.

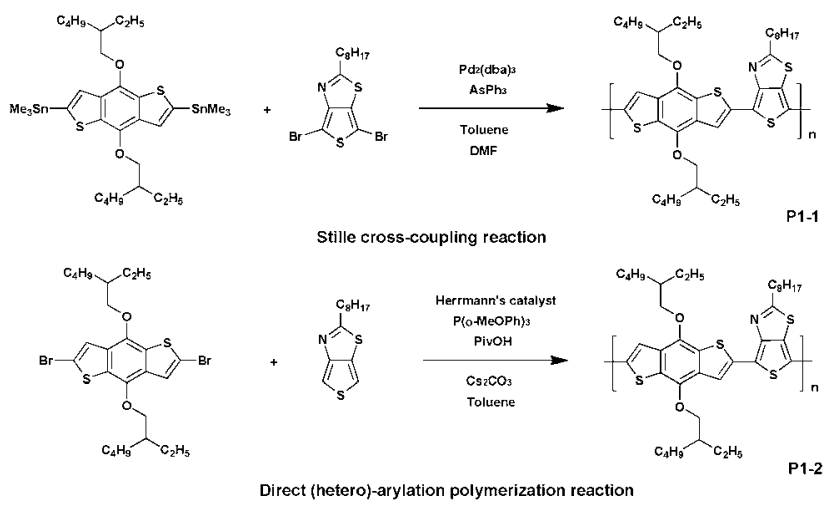

Scheme 1 Preparation of P1-1 via Stille coupling and P1-2 via DHAP.

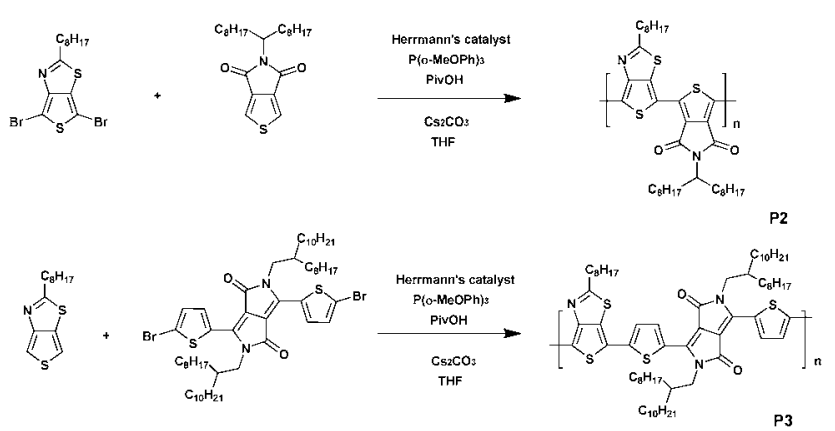

Scheme 2 Synthesis of $\mathbf{P} \mathbf{2}$ and $\mathbf{P} 3$ via DHAP.

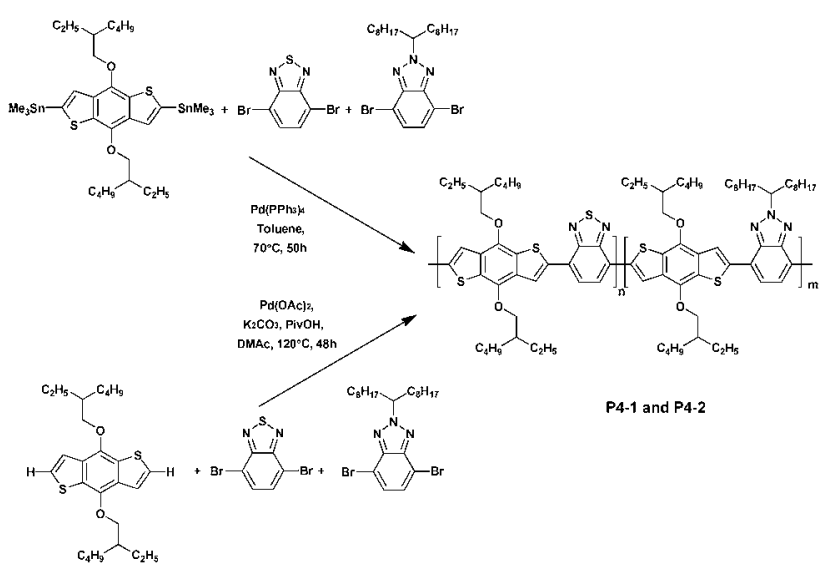

Scheme 3 Preparation of P4-1 via Stille coupling and P4-2 via DHAP.

In 2015, Marzano et al. ${ }^{36}$ reported a new random copolymer prepared via both Stille polymerization (P4-1) and DHAP (P4-2), and which contained two different acceptor units, namely benzo $[c][1,2,5]$ thiadiazole and benzo[ $[d][1,2,3]$ triazole along with one donor moiety, namely benzo[1,2-b;4,5- $\left.b^{\prime}\right]$ dithiophene (Scheme 3). The DHAP afforded the polymer P4-2 in lower yields $\left(70 \%\right.$ vs. $85 \%$ for P4-1) but with longer chains $\left(M_{\mathrm{n}}=\right.$ $10.3 \mathrm{kDa}$ for P4-2 vs. $M_{\mathrm{n}}=20 \mathrm{kDa}$ for P4-1). All polymers synthesized were tested in bulk heterojunction (BHJ) solar cells with [6,6]-phenyl $\mathrm{C} 71$ butyric acid methyl ester $\left(\mathrm{PC}_{71} \mathrm{BM}\right)$. The device based on P4-1 showed a modest power conversion (PCE) of $2.5 \%$. However, after adding $2 \%(\mathrm{v} / \mathrm{v})$ of 1-chloronaphthalene (CN), which was reported to improve the PCEs, ${ }^{37}$ the device performance was significantly increased to $4.8 \%$. Meanwhile, without the additive P4-2, it exhibited a comparable PCE of $c a$. 1.9\%. Upon CN processing the PCE of P4-2 was barely improved to $2.8 \%$, indicating that the polymer $\mathbf{P 4 - 2}$ is almost insensitive to this treatment, probably due to the structural defects of DHAP polymers. ${ }^{38}$

\section{Homopolymers synthesized via DHAP}

Polythiophenes are considered to be part of the most promising material family in both conductive polymers and photovoltaic materials. However, without substituents, the latter are neither soluble nor feasible. To solve this solubility issue, alkyl-substitution 
turns out to be the most effective shortcut. For instance, poly(3alkylthiophene) (P3AT) appears to be the most common polythiophene bearing alkyl-substituted side chains, and the well-known poly-3-hexylthiophene (P3HT) can be cited as a key example. ${ }^{39-41}$ For the most part, polymerization typically occurs in the 2-position and the 5-position of thiophene. If the 2-position is chosen as the "head" (simply as " $\mathrm{H}$ ") of the polythiophene units and the 5-position as the "tail" (simply as "T"), the proportion of the units with "head-to-tail" (HT-HT) structures in the poly(3-alkylthiophene) is called regioregularity. ${ }^{42}$ Due to the small steric hindrance among the repeated units, such a process is more likely to achieve better planarity and stronger interchain interactions. Thus, compared with irregular polythiophene, head-to-tail regioregular (RR) P3ATs have not only elevated the effective conjugated chain length, but also higher charge mobility. ${ }^{43}$

In 2010, Ozawa et $a .^{44}$ reported the palladium-catalyzed direct arylation polymerization of 2-halo-3-hexylthiophene affording RR-P3HT (Scheme 4). The use of Herrmann's catalyst and Tris(2dimethylaminophenyl)phosphine as the ligand lead to the preparation of $\mathbf{P 5}$ characterized by a high molecular weight $\left(M_{\mathrm{n}}=30.6 \mathrm{kDa}\right)$ and a promising regioregularity of $c a .98 \%$ in an almost quantitative yield (99\%). Interestingly, the regioregularity improved significantly with increasing molecular weight, probably because of the cross-coupling reaction between $\mathrm{C}-\mathrm{H}$ and $\mathrm{C}-\mathrm{Br}$, which dominates the polymerization at the later stage. From these experimental data higher regioregularity leads to higher charge mobility and conductivity, therefore improving the PCEs when the polymer is used in BHJ solar cells.

Then in 2015 the DHAP method, which can selectively synthesize unprotected thiophene units under an appropriated catalytic system, was first reported by Bura et al. ${ }^{45}$ The use of the Herrmann-Beller catalyst and $\mathrm{P}\left(o-\mathrm{NMe}_{2} \mathrm{Ph}\right)_{3}$ in the solvent of dioxane with an acidic additive was quite useful to achieve well-defined thiophene-thiophene couplings. A high molecular weight of poly( $3,3^{\prime \prime \prime}$-didodecyl-2,2' $: 5^{\prime}, 2^{\prime \prime}: 5^{\prime \prime}, 2^{\prime \prime \prime}$-quaterthiophene) (PQT12) (P6) (43 kDa) was achieved by synthesizing 5-bromo$3,3^{\prime \prime \prime}$-didodecyl $2,2^{\prime}: 5^{\prime}, 2^{\prime \prime}: 5^{\prime \prime}, 2^{\prime \prime \prime}$-quaterthiophene (monomer A) and 5-bromo-3', $4^{\prime \prime}$-didodecyl-2,2' $: 5^{\prime}, 2^{\prime \prime}: 5^{\prime \prime}, 2^{\prime \prime \prime}$-quaterthiophene (monomer B) (Scheme 5). The experiments undertaken highlighted that adding steric hindrance protection around the $\beta$-positions of the brominated thiophene unit is of great importance to improve the selectivity of the cross-couplings at the $\alpha$-positions. Plus, these experiments also proved that DHAP could be a practicable synthetic tool to obtain various polythiophene derivatives applied in both organic electronics and in the fabrication of photovoltaic devices.

To date, polythiophene is one of only a few homopolymers that can be synthesized via DHAP. Beyond this a wide variety of
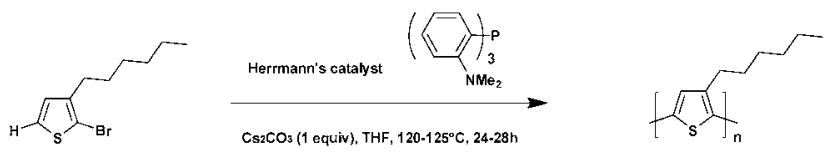

HT-P3HT (P5)

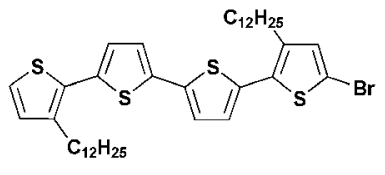

Monomer A

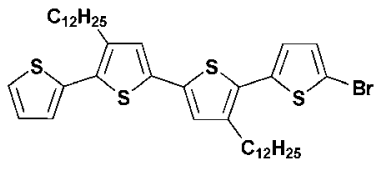

Monomer B

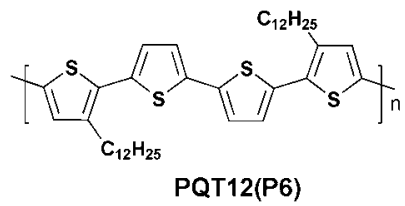

Scheme 5 Synthesis of polythiophene P6 via DHAP.

homopolymers, based on different monomers prepared via DHAP, have been attempted and studied for years. DPP, which is naturally regarded as an acceptor-type building block, is a suitable option. In 2013, Guo et al. ${ }^{46}$ prepared the dithienyldiketopyrrolopyrrole (DTDPP)-based homopolymer P7, which is traditionally synthesized by nickel-mediated Yamamoto-type polycondensation, ${ }^{47}$ using the concise and highly efficient new method, DHAP (Scheme 6). Under the optimized reaction conditions of $5 \mathrm{~mol} \%$ of $\mathrm{Pd}(\mathrm{OAc})_{2}, 10 \mathrm{~mol} \%$ of $\mathrm{PCy}_{3} \cdot \mathrm{HBF}_{4}(\mathrm{Cy}=$ cyclohexyl), 2.5 equivalents of $\mathrm{K}_{2} \mathrm{CO}_{3}$ and 1.0 equivalent of pivalic acid in the mixed solvent of $N, N$-dimethylacetamide (DMAc)/xylene (1:1), the unsymmetrical DTDPP-DTDPP copolymer P7 with different alkyl substituents on each DPP unit ${ }^{48}$ was obtained as a black solid in a moderate yield of $43 \%$ with an $M_{\mathrm{n}}$ of $30.2 \mathrm{kDa}$ and a polymer dispersity index (PDI) of 3.56. The optical and electrochemical properties were also characterized. The UV-vis-NIR absorption spectrum of $\mathbf{P 7}$ in a film on the quartz plate was tested and the absorption band edge ( $\left.\lambda_{\text {onset }}\right)$ was $1014 \mathrm{~nm}$, which showed strong and broad NIR absorption bands. In addition, P7 exhibited a remarkable optical low bandgap $\left(E_{\mathrm{g}}^{\mathrm{opt}}\right)$ down to $1.22 \mathrm{eV}$, which estimated from the absorption band edge in film $\left(\lambda_{\text {onset }}\right)$ was probably due to the common features of ideal planarity and good $\pi$-conjugation. Such structural features may make it a promising feature in OPV materials.

\section{D-A conjugated polymers synthesized via DHAP}

\subsection{Polymers containing benzothiadiazole (BT)}

Benzothiadiazole (BT) is an altogether applicable acceptor unit exceptionally suited for photovoltaic materials owing to its appropriate electron-withdrawing ability. Retaining a relative low highest occupied molecular orbital (HOMO) energy level in

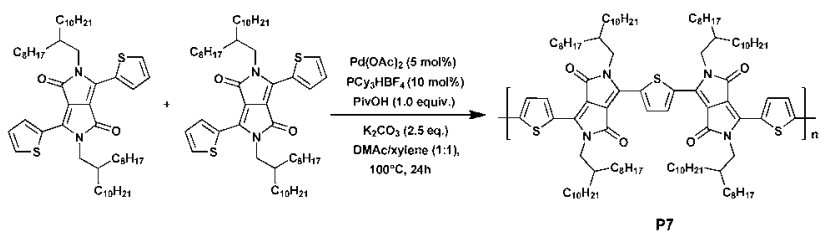

Scheme 6 Synthesis of homopolymer P7 via DHAP.

Scheme 4 Synthesis of regioregular polymer P3HT via DHAP. 


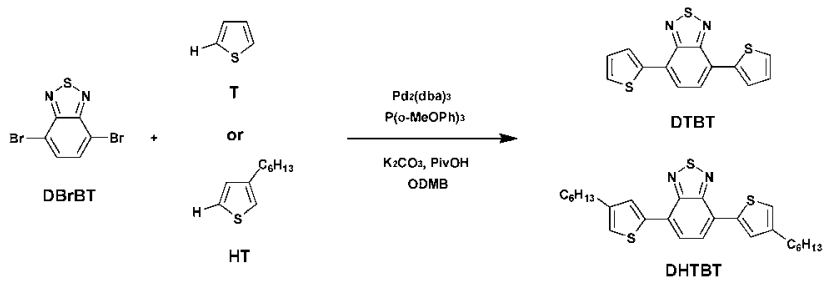

Scheme 7 Synthesis of the small molecules DTBT and DHTBT.

the copolymers, which is advantageous for the chemical stability of the copolymers as well as for attaining a high open-circuit voltage $\left(V_{\text {oc }}\right)$ in the final organic photovoltaics, makes it stand out among the numerous acceptor groups (such as thienothiadiazole, thienopyrazine, etc.). ${ }^{4-51}$ Consequently, BT has become an extremely important building block utilized in efficient photovoltaic materials. And the utilization of a BT unit in push-pull conjugated polymers has shown a high PCE of up to $9.1 \%$ in dye-sensitized solar cells. ${ }^{52}$

Wang et al. ${ }^{53}$ recently reported the synthesis of small molecules containing bare thiophene, alkyl-substituted thiophene and 4,7-dibromo-2,1,3-benzothiadiazole (DBrBT) (Scheme 7). Under optimized conditions, $\mathrm{Pd}_{2}(\mathrm{dba})_{3}$-catalyzed DHAP produced the corresponding small molecules, i.e., a thiophene-flanked benzothiadiazole derivative (DTBT) and 4,7-bis(4-hexylthiophen-2-yl)2,1,3-benzothiadiazole (DHTBT), with a comparable yield to that of the reference Stille or Suzuki coupling reactions.

DTBT and DHTBT were then used respectively to synthesize conjugated polymers PFTBT (P8) and PFHTBT (P9) with 9,9dioctyl-2,7-dibromofluorene (DBrF) still via DHAP in high yield, i.e., $82 \%$ and $91 \%$, respectively. In addition, $\mathbf{P 8}$ was characterized by an $M_{\mathrm{n}}$ of $13.8 \mathrm{kDa}$ while $\mathbf{P 9}$ was characterized by a slightly higher $M_{\mathrm{n}}$ of $17.6 \mathrm{kDa}$. Due to the presence of hexyl side chains on the thiophene units the solubility of P9 was remarkably improved compared to P8. According to the high-temperature NMR, this method of DHAP catalyzed with $\mathrm{Pd}_{2}(\mathrm{dba})_{3}$ allows the synthesis of almost defect-free polymers with good $\mathrm{C}-\mathrm{H}$ selectivity. Furthermore, it is worth noting that $\mathbf{P 9}$ exhibits a hypsochromicshifted absorption spectrum compared with a $\mathbf{P 8}$ of $c a .35 \mathrm{~nm}$, attributed to the steric hindrance of the hexyl groups on the thiophene rings. Indeed, it is supposed that the $\pi$-conjugation along the backbone in $\mathbf{P 9}$ could impede by the increasing dihedral angles between the thiophene and the fluorene unit (Scheme 8). ${ }^{54}$

In 2016, Tomar et al..$^{55}$ reported four donor-acceptor type polymers based on benzothiadiazole and thiophene-benzothiadiazole-thiophene (TBTT) synthesized via DHAP (Scheme 9).

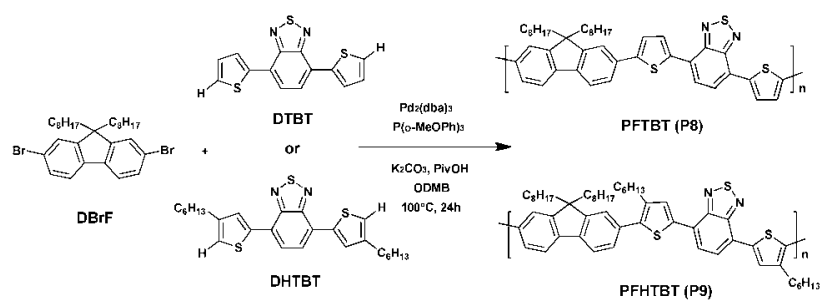

Scheme 8 Synthesis of P8 and P9 via DHAP under the same conditions.
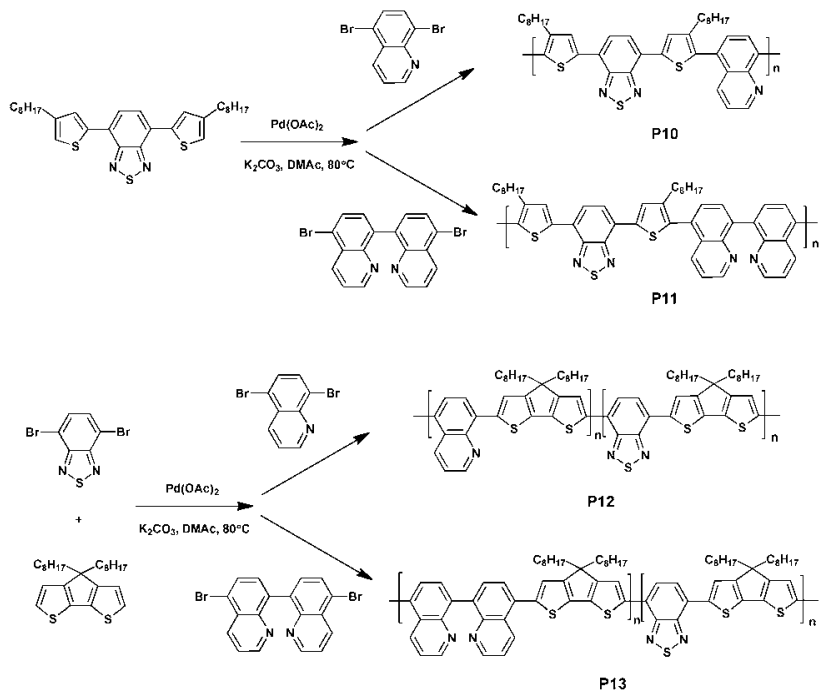

Scheme 9 Synthesis of P10-P13 via DHAP.

Under the optimal conditions of $\operatorname{Pd}(\mathrm{OAc})_{2}$, pivalic acid, DMAc at $80{ }^{\circ} \mathrm{C}$ and in a nitrogen atmosphere, alternate polymers $\mathbf{P 1 0}$ and P11 were achieved by reacting thiophene-benzothiadiazolethiophene with quinoline and biquinoline, respectively; a random polymer P12 was achieved by reacting benzothiadiazole, cyclopentadithiophene (CPDT) and quinoline; and P13 was obtained using biquinoline instead of quinoline. All polymers exhibited good solubility in ordinary organic solvents and the numberaverage molecular weights of $3.6 \mathrm{kDa}, 5.03 \mathrm{kDa}, 5.3 \mathrm{kDa}$ and $7.6 \mathrm{kDa}$ were obtained by the measurements of gel permeation chromatography against polystyrene standards. The UV/Vis absorption spectra of the four polymers were then investigated, which revealed that P10 (494 nm) and P12 (664 nm) showed a higher value of absorbance maxima compared to P11 (481 nm) and P13 $(649 \mathrm{~nm})$ on account of more efficient electron delocalization caused by the more planar structure. ${ }^{56,57}$ In addition, the deep-lying HOMO energy levels of P10, P11, P12 and P13, which were $-5.82 \mathrm{eV}$, $-5.75 \mathrm{eV},-5.19 \mathrm{eV}$, and $-5.03 \mathrm{eV}$, respectively, showed improved oxidative stability for this variety of polymers. Furthermore, OFET characteristics were also studied. P12 and P13 could be observed exhibiting a hole-type transport of $11 \times 10^{-3} \mathrm{~cm}^{2} \mathrm{~V}^{-1} \mathrm{~s}^{-1}$ and $6 \times 10^{-3} \mathrm{~cm}^{2} \mathrm{~V}^{-1} \mathrm{~s}^{-1}$, respectively, whereas P10 and P11 did not show any OFET characteristics due to the existence of the dominant contact resistance in the P10 and P11 systems.

\subsection{Polymers containing thieno[3,4-c]pyrrole-4,6-dione (TPD)}

The TPD unit is a good electron-withdrawing co-monomer, which has great potential for photovoltaic applications. Indeed, recent studies reported that some highly efficient TPD-based PSCs exhibit a PCE of up to $8.5 \%$ when fabricated and tested under an inert atmosphere. ${ }^{58-61}$ Its relatively planar structure could prove to be beneficial for electron delocalization when incorporated into conjugated polymers promoting intra-molecular/ intermolecular interactions. In addition, its strong electronwithdrawing effect could lead to low HOMO and lowest unoccupied molecular orbital (LUMO) energy levels. ${ }^{22}$ For these reasons 
the TPD based materials were shown to be good electron donors when synthesizing donor-acceptor conjugated polymers, developing specific interactions between the imide group and the fullerene derivatives. ${ }^{62}$ Moreover, the imide group in the TPD moiety could also be used as a directional activating group so that $\mathrm{C}-\mathrm{H}$ activation could typically occur in the 2-position and the 5-position of thiophene. $^{63}$

In 2012, Leclerc et al. ${ }^{64}$ synthesized a TPD-bithiophene based polymer via DHAP in high yield (96\%). Under optimal conditions, using Tris(3-methoxyphenyl)phosphine as the ligand and $\mathrm{Pd}(\mathrm{OAc})(\mathrm{o}$-Tol $)$ as the catalyst, high molecular weights of ca. $60 \mathrm{kDa}$ were achieved. In parallel, the Stille polymerization was carried out using $\operatorname{Pd}_{2}(\mathrm{dba})_{3}$ as the catalyst and Tris(3methoxyphenyl)phosphine as the ligand. The resulting polymer (P14-2) showed a lower yield (71\%) and molecular weight $\left(M_{\mathrm{n}}\right.$ of $9 \mathrm{kDa}$ ). The UV/Vis absorption spectra of the two analogues were then investigated and revealed that both P14-1 and P14-2 exhibit comparable features in chloroform solutions and in the solid-state. However, compared to P14-2 the absorption maximum of P14-1 is slightly red shifted, by $c a .18 \mathrm{~nm}$ in film, probably because of the different molecular weights and morphologies/ packing in the solid state. Additionally, X-ray and thermal analyses were performed to study the structural regularity of these polymers, showing that both the enthalpies of crystallization and melting were higher for P14-1 than for P14-2 (Scheme 10).

In 2012, two TPD based polymers, namely P15 and P16, containing bithiophene or terthiophene as electron-rich moieties, respectively, were prepared by Jo et al. ${ }^{65}$ via a direct heteroarylation procedure in the presence of trans-di( $\mu$-acetato)bis[ $o$-(dio-tolylphosphino)benzyl]dipalladium(II) and Tris(o-methoxyphenyl)phosphine (Scheme 11). The bithiophene-containing polymer P15 achieved 94\% yield and was characterized by a $M_{\mathrm{n}}$ of $50 \mathrm{kDa}$ while P16 barely reached a $M_{\mathrm{n}}$ of $41 \mathrm{kDa}$ with a similar yield (92\%). Furthermore, it is worth noting that these polymers exhibit HOMO energy levels of ca. $-5.66 \mathrm{eV}$. From this, BHJ solar cells based on photoactive films made of a blend of P15 or P16 with [6,6]-phenyl C71-butyric acid methyl ester $\left(\mathrm{PC}_{70} \mathrm{BM}\right)$ were fabricated. Upon optimization, PCEs of $1.90 \%$ and $6.10 \%$ were obtained from the P15 and P16 based devices, respectively. These differences are probably induced by the terthiophene unit
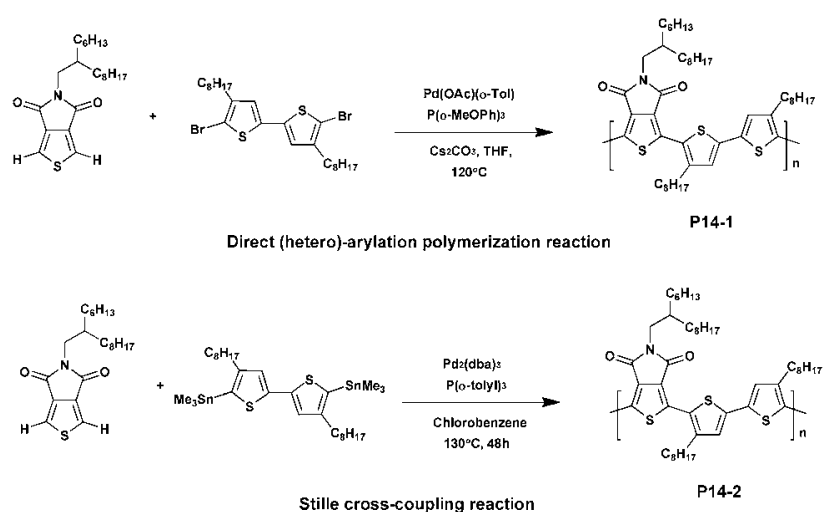

Scheme 10 Preparation of P14-1 via DHAP and P14-2 via Stille coupling.

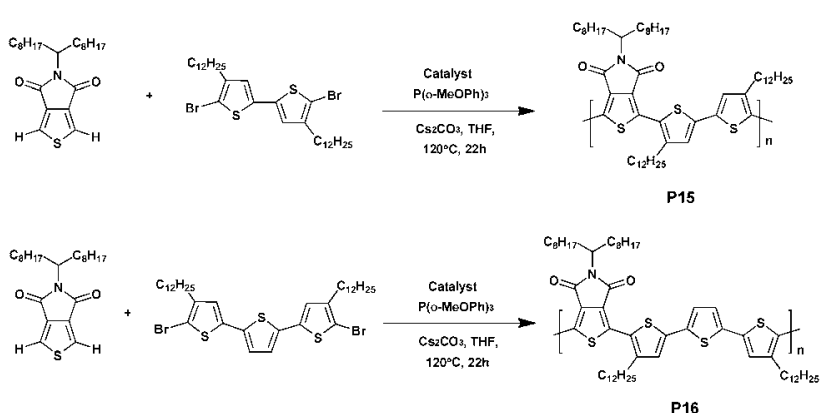

Scheme 11 Synthesis of P15 and P16 via DHAP.

favouring better conjugation along the backbone, higher electron mobility and better $\pi-\pi$ stacking. ${ }^{66}$ Indeed, it is noteworthy that the absorption spectrum of $\mathbf{P 1 6}$ exhibits a vibronic shoulder at $600 \mathrm{~nm}$, indicating that the polymer chains were already aggregated in solution. Moreover, this peculiar aggregation shows that integrating the polymers into field-effect transistors led to a better charge carrier mobility $\left(1.3 \times 10^{-2} \mathrm{~cm}^{2} \mathrm{~V}^{-1} \mathrm{~s}^{-1}\right.$ for $\mathbf{P 1 6}$ vs. $10^{-5} \mathrm{~cm}^{2} \mathrm{~V}^{-1} \mathrm{~s}^{-1}$ for P15).

Despite its multiple advantages, including simplified steps and no need for preprocessing the organometallic monomers, DHAP still suffers from two main limitations: the first one concerns the homocoupling reaction leading to structural defects of the polymer chains, ${ }^{67-70}$ and the second deals with the lack of selectivity when different $\mathrm{C}-\mathrm{H}$ bonds are present causing branching as well as cross-linking and generally leading to insoluble materials. ${ }^{71-73}$

However, in 2016, Ozawa et al. ${ }^{74}$ studied these two questions by exploring an original strategy (Scheme 12). When preparing P17, composed of a dithienopyrrole unit as the donor and the TPD unit as the acceptor, they found that using a blend of ligands in palladium catalyzed direct arylation polymerizations may avoid side reactions effectively and favor high yield. Thus, the combined use of Tris(2-methoxyphenyl)phosphine and tetramethylethylenediamine in the presence of $\operatorname{Pd}_{2}(\mathrm{dba})_{3}$ led to a high yield, reduced defect formation and no insoluble materials.

\subsection{Polymers containing isoindigo}

Isoindigo is an ideal building block for synthesizing D-A conjugated polymers. Indeed, the latter displays many advantages such as a strong electron-withdrawing character, outstanding stability, a highly fused structure, outstanding absorption properties, and so on. ${ }^{75-77}$ As a result, polymers of isoindigo generally show low bandgaps, strong $\pi-\pi$ interactions and high charge carrier mobility, suggesting a potential compatibility in building D-A polymers for efficient organic photovoltaic materials. ${ }^{78-81}$ High performance $\mathrm{BHJ}$ solar cells based on isoindigo polymers have

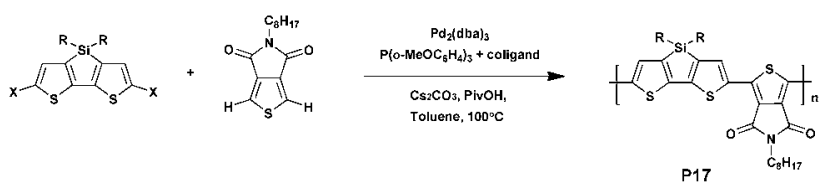

Scheme 12 Preparation of P17 via DHAP. 
already been fabricated with PCEs of up to $7 \%,{ }^{82-84}$ and fieldeffect transistors with a mobility as high as $3.62 \mathrm{~cm}^{2} \mathrm{~V}^{-1} \mathrm{~s}^{-1} \cdot{ }^{85-87}$

Moreover, while generally used as a p-type material, only a few studies have been devoted to afford n-type isoindigo-based materials. In 2013, Grenier et al. ${ }^{88}$ combined three different electron-withdrawing co-monomers with a low steric hindrance, namely TPD, the $5,5^{\prime}$-dioctyl-1, $1^{\prime}-4 H$-bithieno[3,4-c]pyrrole$4,4^{\prime}, 6,6^{\prime}\left(5 H, 5^{\prime} H\right)$-tetrone (BTPD) or DPP with the isoindigo to prepare n-type copolymers characterized by good charge mobility, low bandgaps and low energy levels. At first, the three copolymers were synthesized via Suzuki-Miyaura cross-coupling reaction. However, only P18 could be isolated with an acceptable yield of ca. $70 \%$ and a $M_{\mathrm{n}}$ of $44 \mathrm{kDa}$ (Scheme 13).

From these observations, the synthesis of the two other copolymers was carried out via DHAP (Scheme 14). After optimization, P19 and P20 were isolated in 77\% and $87 \%$ yields, respectively, and exhibit a $M_{\mathrm{n}}$ of $24 \mathrm{kDa}$ and $20 \mathrm{kDa}$, respectively. From the respective cyclic voltammograms (CV) and UV-abs, the energy levels of the copolymers P19 and P20 were found to be relatively stabilized with LUMO levels of around $-4.2 \mathrm{eV}$, i.e., close to that of $\mathrm{PC}_{61} \mathrm{BM} .{ }^{89}$ Moreover, while these two polymers show no electrochemical reversibility in the oxidation process, polymer P18 shows reversibility in its oxidation as well as reduction. In addition, the latter is characterized by a higher LUMO energy level of $-4.0 \mathrm{eV}$ and a HOMO energy level of $-5.3 \mathrm{eV}$. As a result, $\mathbf{P 1 9}$ and $\mathbf{P 2 0}$ could be ideal candidates as n-type polymers and can possibly be used in all-polymer solar cells. In parallel, thin film transistor properties were investigated. P19, P20 and P18 exhibit electron mobilities of ca. $2.0 \times$ $10^{-4} \mathrm{~cm}^{2} \mathrm{~V}^{-1} \mathrm{~s}^{-1}, 2.5 \times 10^{-3} \mathrm{~cm}^{2} \mathrm{~V}^{-1} \mathrm{~s}^{-1}$ and $1.6 \times$ $10^{-4} \mathrm{~cm}^{2} \mathrm{~V}^{-1} \mathrm{~s}^{-1}$, respectively, suggesting that using a BTPD unit instead of a TPD unit contributes to increase the electron mobility due to the centrosymmetric structure of the BTPD unit.

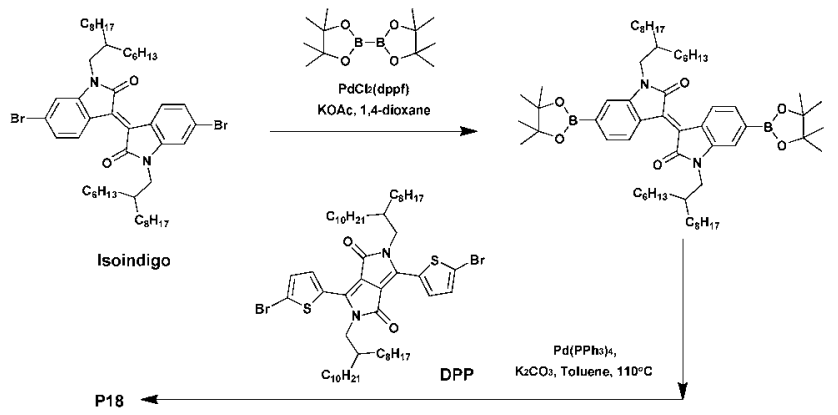

Scheme 13 Synthesis of P18 via Suzuki-Miyaura coupling.
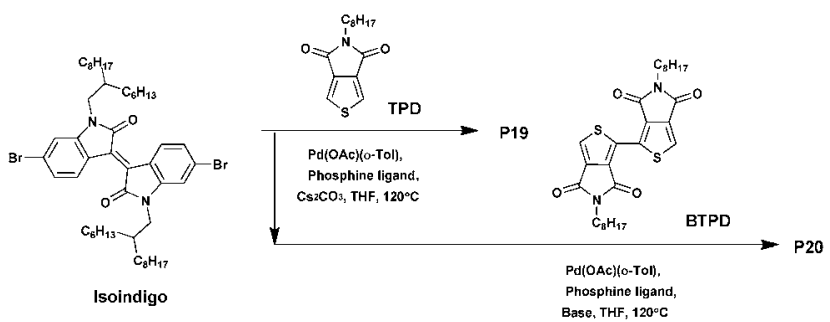

Scheme 14 Synthesis of P19 and P20 via DHAP.
Indeed, because of the improved packing properties, copolymers containing isoindigo and centrosymmetric co-monomers may have higher charge transport properties. ${ }^{90}$ Finally, these results show an almost comparable electron mobility of that characterizing $\mathrm{PC}_{61} \mathrm{BM}$ in the thin film $\left(\sim 10^{-3} \mathrm{~cm}^{2} \mathrm{~V}^{-1} \mathrm{~s}^{-1}\right)^{91,92}$ meaning that they can have promising features and great potential as n-type materials in organic photovoltaics.

Furthermore, Elsawy et $a .^{93}$ recently reported the synthesis and characterization of a series of $\mathrm{D}-\mathrm{A}-\mathrm{D}-\mathrm{A}^{\prime}$ copolymers incorporating different strong acceptors, i.e., the isoindigo (A) unit and 4,7-dibromo[c][1,2,5]-(oxa, thia, or selena)diazole $\left(\mathrm{A}^{\prime}\right)$ with 3,4-ethylenedioxythiophene as the donor (D) via DHAP (Scheme 15). In this study, the effects of different heteroatoms namely the oxygen, sulfur and selenium borne by the benzimidazole unit on the photovoltaic properties were investigated. At first, the authors prepared the $6,6^{\prime}$-bis(2,3-dihydrothieno[3,4-b][1,4]-dioxin5-yl)1,1'-bis-(2-octyldodecyl)-[3,3'-biindolinylidene]-2,2'-dione (IDED) polymer via conventional Stille coupling reaction with a high yield of ca. 80\%. Then the preparation of three polymers, namely PIDEDO (P21), PIDES (P22) and PIDEDSe (P23), was carried out under $\mathrm{CH}$-arylation activation in high yields $(>80 \%)$. Molecular weights ranging from $15.2 \mathrm{kDa}$ to $17.3 \mathrm{kDa}$ were estimated using gel permeation chromatography. Thin-film UV/Vis spectra exhibit red-shifted absorption profiles demonstrating more $\pi-\pi$ stacking and ordering in the solid state. In addition, moving from $\mathrm{O}$ to Se results in a bathochromic shift with a difference of ca. $68 \mathrm{~nm}\left(\lambda_{\max }\right)$ between $\mathbf{P 2 1}$ and $\mathbf{P 2 3}$.

Next, the photovoltaic performances of three polymers as donor materials were assessed through the preparation of $\mathrm{PC}_{61} \mathrm{BM}$ based BHJ. The device performances are summarized in Table 1. Compared with the P21-based device, the PCEs of the two other devices were significantly higher, due to the well-improved shortcircuit current density $\left(J_{\mathrm{sc}}\right)$ parameters. This enhancement can be attributed to the higher electron densities and the appropriate morphology of the films. ${ }^{94}$ Moreover, a comparison of thiophene and selenophene based devices revealed a superior charge balance of the P22: $\mathrm{PC}_{61} \mathrm{BM}$ blend resulting in its higher $J_{\mathrm{sc}}$.

The charge transport properties of each material were estimated using OFETs and the hole mobilities of $1.9 \times 10^{-4}$, $4.0 \times 10^{-4}$ and $3.5 \times 10^{-4} \mathrm{~cm}^{2} \mathrm{~V}^{-1} \mathrm{~s}^{-1}$ were measured for $\mathbf{P 2 1}$, $\mathbf{P 2 2}$ and P23, respectively. From Table 2, the blend of P22:PC ${ }_{61} \mathrm{BM}$

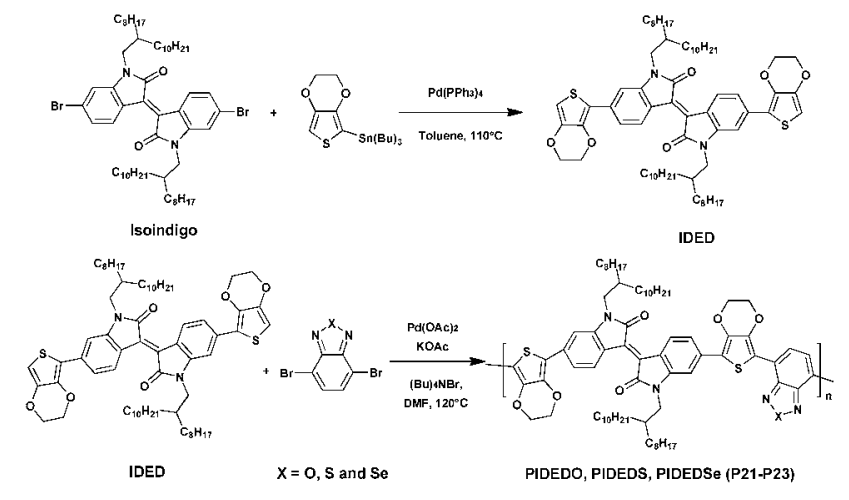

Scheme 15 Preparation of P21-P23 via DHAP 
Table 1 Photovoltaic performances of P21, P22 and P23

\begin{tabular}{lllll}
\hline Active layer & $J_{\text {sc }}\left(\mathrm{mA} \mathrm{cm}^{-2}\right)$ & $V_{\text {oc }}(\mathrm{V})$ & FF $(\%)$ & PCE (\%) \\
\hline P21 & 2.27 & 0.58 & 46.0 & 0.61 \\
P22 & 8.10 & 0.56 & 35.0 & 1.60 \\
P23 & 7.13 & 0.56 & 34.0 & 1.36
\end{tabular}

\begin{tabular}{|c|c|c|}
\hline Active layer & $\mu_{\mathrm{e}}\left(\mathrm{cm}^{2} \mathrm{~V}^{-1} \mathrm{~s}^{-1}\right)$ & $\mu_{\mathrm{h}}\left(\mathrm{cm}^{2} \mathrm{~V}^{-1} \mathrm{~s}^{-1}\right)$ \\
\hline P21:PC ${ }_{61} \mathrm{BM}$ & $1.85 \times 10^{-6}$ & $5.41 \times 10^{-4}$ \\
\hline P22: $\mathrm{PC}_{61} \mathrm{BM}$ & $2.31 \times 10^{-4}$ & $4.46 \times 10^{-4}$ \\
\hline P23: $\mathrm{PC}_{61} \mathrm{BM}$ & $7.45 \times 10^{-5}$ & $2.25 \times 10^{-4}$ \\
\hline
\end{tabular}

exhibits the highest electron mobility and a good charge balance due to its appropriate film morphology.

Although high yields and high molecular weights of isoindigobased copolymers are reachable via DHAP, the biggest challenge still remains, that being its reproducibility. In this context, Leclerc et al. ${ }^{6}$ reported for the first time continuous flow methods applied to DHAP. This inexpensive technology uses a reactor under fixed and constant reaction conditions. ${ }^{95,96}$ From this set up a new D-A polymer containing a strong electron-donating unit, namely 3,4-ethylenedioxythiophene (EDOT), and isoindigo (iI) as the acceptor (A), was synthesized and characterized with an $M_{\mathrm{n}}$ ranging from 34 to $42 \mathrm{kDa}$ (Scheme 16). In addition, OFET and $\mathrm{BHJ}$ solar cells were fabricated to estimate the charge carrier mobility and organic photovoltaic performance, respectively. A comparison of PiIEDOT (P24) synthesized in a conventional flask reveals a similar hole mobility of $c a .2 \times 10^{-3} \mathrm{~cm}^{2} \mathrm{~V}^{-1} \mathrm{~s}^{-1}$ and a comparable PCE of $c a .1 .74 \%$ and $1.80 \%$, respectively, when blended with $\mathrm{PC}_{71} \mathrm{BM}$. Although the $V_{\mathrm{oc}}$ and fill factor (FF) are nearly identical, the main limitation, impacting the PCEs, comes from the low $J_{\mathrm{sc}}$ recorded in both cases $\left(5.0 \mathrm{~mA} \mathrm{~cm}{ }^{-2}\right)$. However, it is noteworthy that both polymers exhibit comparable molecular weights. Consequently, these promising results confirm the great potential of the continuous flow methods.

\subsection{Polymers containing diketopyrrolopyrrole (DPP)}

Due to the strong electron-withdrawing nature, intermolecular hydrogen bonding, planar backbone and strong $\pi-\pi$ stacking interactions, the DPP moiety has been widely used for the preparation of active macromolecules. ${ }^{97-99}$ For instance, high performance DPPbased polymers with PCEs of up to $8 \%$ were reported. ${ }^{100-102}$

Recently, Kuwabara et al. ${ }^{103}$ discussed the optimization of reaction conditions for the synthesis of height diketopyrrolopyrrolebased conjugated polymers via DHAP (Scheme 17). In this study,
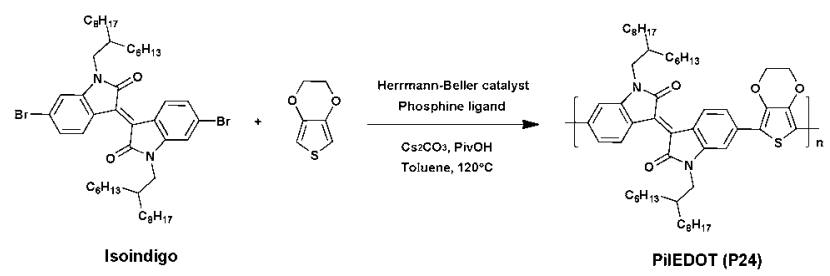

Scheme 16 Polymerization of P24 via DHAP.

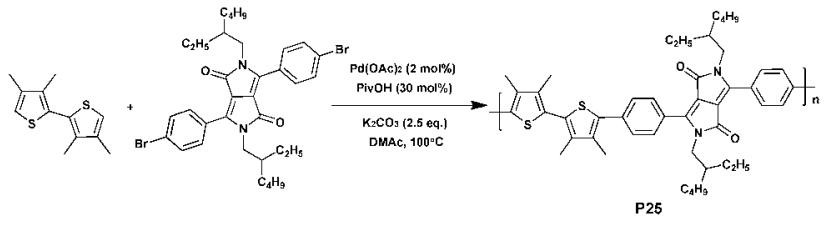

Scheme 17 Synthesis of P25 via DHAP

Kuwabara et al. report on the importance of reaction time to afford high-molecular-weight polymers in DHAP while avoiding overreactions in unexpected $\mathrm{C}-\mathrm{H}$ bonds. Thus, polymer $\mathbf{P 2 5}$ (copolymerized by 2,5-di-(2-ethylhexyl)-3,6-bis(4-bromophenyl)pyrrolo[3,4-c]pyrrole-1,4-dione and 3,3',4,4'-tetramethylbithiophene) was synthesized with a reaction time of $6 \mathrm{~h}$, isolated in good yield, and characterized by a high molecular weight $\left(M_{\mathrm{n}}\right.$ of $18.1 \mathrm{kDa}$ ). Moreover, since the polymer shows wide absorption in the visible region, as well as the low-lying HOMO energy level, it was investigated as a potential donor in $\mathrm{BHJ}$ solar cells. ${ }^{89,104}$ When blended with $\mathrm{PC}_{61} \mathrm{BM}$, a $V_{\mathrm{oc}}$ of $1.01 \mathrm{~V}$, a $J_{\mathrm{sc}}$ of $2.93 \mathrm{~mA} \mathrm{~cm}^{-2}$, a FF of 0.30 and a resulting PCE of $0.89 \%$ were achieved for P25. The device exhibited high $V_{\text {oc }}$ attributed to the low-lying HOMO energy level and an optimized morphology. The low $J_{\mathrm{sc}}$ and FF may be due to the twisted structure of the polymer, which is not suitable for carrier transport. ${ }^{105,106}$ Even though the PCE value of the device is much lower than those typically recorded using P3AT-based devices, ${ }^{107-109}$ the results of this study point out that DHAP can be used commendably to synthesize polymers for PSCs. ${ }^{110}$

Guo et al. ${ }^{46}$ conducted a series of studies on DTDPP-based polymers synthesized via DHAP in 2013 (Scheme 18). The DTDPP-based copolymers exhibited outstanding photoelectronic properties, such as a low bandgap and high hole mobilities, making them key prospects for application in optoelectronic materials. ${ }^{111}$ Under the optimized reaction conditions of $5 \mathrm{~mol} \%$ of $\mathrm{Pd}(\mathrm{OAc})_{2}, 10 \mathrm{~mol} \%$ of $\mathrm{PCy}_{3} \cdot \mathrm{HBF}_{4}(\mathrm{Cy}=$ cyclohexyl), 2.5 equivalents of $\mathrm{K}_{2} \mathrm{CO}_{3}$ and 1.0 equivalents of pivalic acid in the mixed solvent of DMAc/xylene (1:1), both electron-donating units (P28, P29, P30 and P31) and electron-withdrawing units (P26 and P27) were successfully

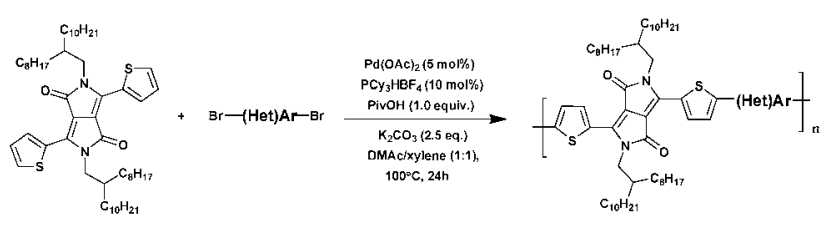

(Het)Ar $=$

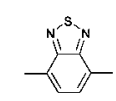

P26 (PDTDPP-BT)

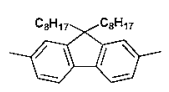

P29 (PDTDPP-F)
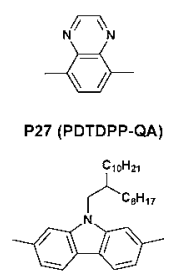

P30 (PDTDPP-C2)

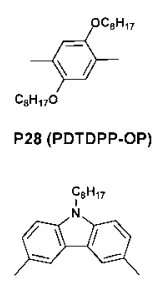

P31 (PDTDPP-C3)
Scheme 18 Synthesis of P26-P31 via DHAP. 
Table 3 Molecular weights, PDI and yields of P26-P31

\begin{tabular}{llll}
\hline Polymer & $M_{\mathrm{n}}(\mathrm{kDa})$ & PDI & Yield $(\%)$ \\
\hline P26 & 23.5 & 4.13 & 90 \\
P27 & 23.5 & 4.36 & 92 \\
P28 & 36.7 & 3.46 & 94 \\
P29 & 27.7 & 1.72 & 35 \\
P30 & 45.0 & 3.23 & 90 \\
P31 & 10.2 & 1.73 & 91
\end{tabular}

Table 4 Optical, electrochemical properties of P26-P31

\begin{tabular}{lccllll}
\hline & \multicolumn{2}{l}{ UV-vis absorption spectra } & & \multicolumn{2}{c}{ Cyclic voltammetry } \\
Polymer & $\lambda_{\text {onset }}(\mathrm{nm})$ & $E_{\mathrm{g}}^{\mathrm{opt}}(\mathrm{eV})$ & & HOMO $(\mathrm{eV})$ & LUMO $(\mathrm{eV})$ & $E_{\mathrm{g}}^{\mathrm{CV}}(\mathrm{eV})$ \\
\hline P26 & 1015 & 1.22 & -5.29 & -3.70 & 1.59 \\
P27 & 1010 & 1.23 & -5.17 & -3.64 & 1.53 \\
P28 & 932 & 1.33 & -5.11 & -3.68 & 1.43 \\
P29 & 885 & 1.40 & -5.38 & -3.56 & 1.82 \\
P30 & 923 & 1.34 & -5.10 & -3.62 & 1.48 \\
P31 & 909 & 1.36 & -5.00 & -3.64 & 1.36
\end{tabular}

achieved with high yields of up to $94 \%$ and comparable molecular weights of up to $45 \mathrm{kDa}$ (summarized in Table 3).

What's more, the optical and electrochemical properties of the polymers are characterized and summarized in Table 4.

Compared with the analogues synthesized through Suzuki or Stille coupling reported previously, ${ }^{112-115}$ polymers based on DHAP showed a difference of about 10-40 $\mathrm{nm}$ in the absorption maxima, which may be interpreted as the diverse $M_{\mathrm{n}}$, branching structures from the side reactions and morphology in the solid state. In comparison with the three polymers P28, P29 and P30, P26 and P27 exhibited broader absorption bands (up to $1000 \mathrm{~nm}$ ) and bathochromic shifted absorption maxima. These phenomena imply that a donor-acceptor-donor-acceptor (D-A-D-A) sequence involving DTDPP (regarded as an inherent D-A-D unit) and an acceptor unit offers advantages for the red shift of the absorption band. ${ }^{113}$ In addition, $\mathbf{P 2 6}$ and $\mathbf{P 2 7}$ exhibited remarkable optical bandgaps ( $E_{\mathrm{g}}^{\text {opt }}$ ) down to $1.22 \mathrm{eV}$, which were estimated from the absorption band edge in film $\left(\lambda_{\text {onset }}\right)$. Additionally, the bandgaps $\left(E_{\mathrm{g}}^{\mathrm{CV}}\right)$ estimated using CV were somewhat larger than $E_{\mathrm{g}}^{\mathrm{opt}}$, which can be attributed to the exciton binding energy of polymers between the polymer film and the electrode. ${ }^{115,116}$ So DHAP can not only offer an approach to select low-bandgap and NIR absorbing polymers, but can also accelerate the discovery of high-performance organic photovoltaics.

In 2015, Homyak et al. ${ }^{117}$ used a synthetic method of DHAP to prepare four DPP-based polymers (Scheme 19). High molecular weight $\left(M_{\mathrm{n}}\right)$ polymers ranging from 10 to $30 \mathrm{kDa}$ were obtained; the polymers were applied in OPV as well as OFET devices. While PDPPTTT (P32) and PDPPTPT (P33) achieved an average PCE of 3.8-3.9\%, their fluorinated analogues (PDPPTTfT (P34) and PDPPTPfT (P35)) show much lower efficiencies mainly due to an inappropriate energy gap between the LUMO energy levels of the polymers and the fullerene derivative. However, although OFET devices revealed that all materials showed high hole mobilities within the same order of magnitude (ca. $10^{-2} \mathrm{~cm}^{2} \mathrm{~V}^{-1} \mathrm{~s}^{-1}$ ), values obtained for the fluorinated derivatives P34 and P35

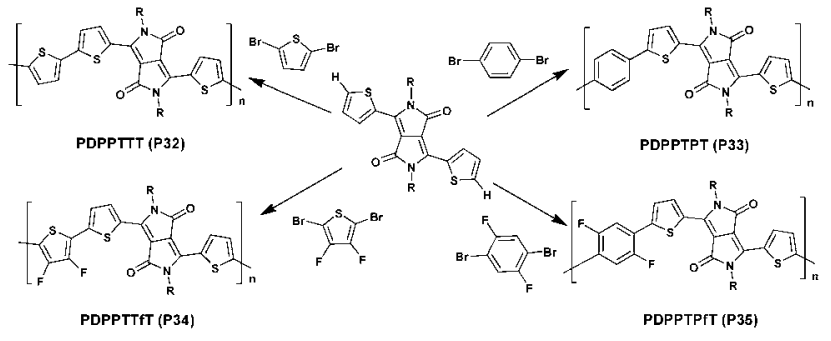

Scheme 19 Synthesis of P32-P35 via DHAP
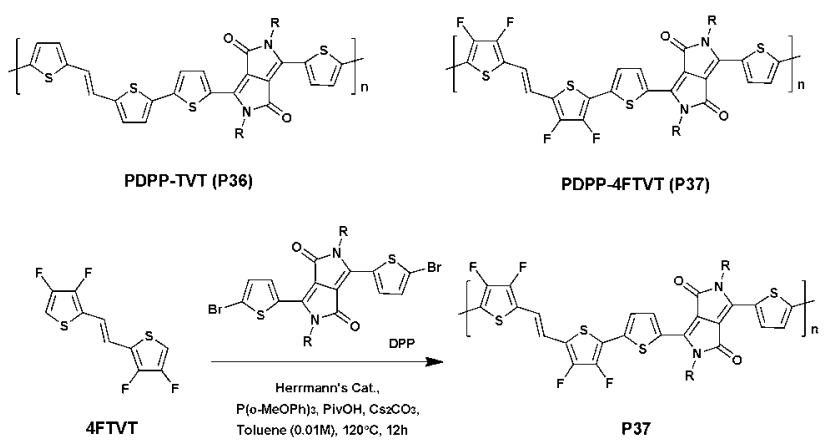

Scheme 20 Polymerization of P36 and P37 via DHAP.

materials are 2-3 times higher than that for the P32 and P33 materials.

To further improve the charge transport properties, the use of oligothiophene derivatives appears to be an effective option. ${ }^{118}$ However, the latter often display low reactivity when involved in direct arylation, ${ }^{119}$ and the multiple $\mathrm{C}-\mathrm{H}$ bonds borne by the aromatic rings may lead to undesired cross-linked defects. ${ }^{72,120,121}$ Consequently, to solve these problems fluorine-atoms were introduced in the $\beta$-positions of thiophene rings (position 3 and 4) and a new DPP-based high-mobility conjugated polymer containing (E)-1,2-bis(3,4-difluorothien-2-yl)ethene (4FTVT) was synthesized via DHAP in high yield (93\%) by Gao et al. ${ }^{122}$ (Scheme 20). Under optimal conditions using Herrmann's catalyst, a polymer with an $M_{\mathrm{n}}$ of $60 \mathrm{kDa}$ was obtained.

The HOMO and LUMO energy levels of PDPP-4FTVT (P37) were estimated using $\mathrm{CV}$ and UV-abs. The incorporation of a fluorine-atom resulted in a significant stabilization of both the HOMO and LUMO energy levels $(-5.36 \mathrm{eV}$ and $-3.50 \mathrm{eV} v s .5 .17 \mathrm{eV}$ and $-3.35 \mathrm{eV}$ for the reference material PDPP-TVT (P36)). From bottom-gate and top-contact OFETs P37 shows ambipolar characteristics and a hole mobility $\left(\mu_{\mathrm{h}}\right)$ of $c a .3 .40 \mathrm{~cm}^{2} \mathrm{~V}^{-1} \mathrm{~s}^{-1} v s$. an electron mobility $\left(\mu_{\mathrm{e}}\right)$ of $c a .5 .86 \mathrm{~cm}^{2} \mathrm{~V}^{-1} \mathrm{~s}^{-1}$. It is noteworthy that these values are comparable to those reached by analogous polymers synthesized via the Stille cross coupling reaction. ${ }^{123-127}$

\section{Summary and outlook}

This review summarizes and gathers data on several donor-acceptor conjugated polymers synthesized via direct(hetero)-arylation polymerization with applications in organic electronics. The use of DHAP as a route toward the formation of the specific 
$\mathrm{C}-\mathrm{C}$ bond has been a great challenge in organic chemistry over the past twenty years, but the results reported herein clearly demonstrate that the way has been paved. According to the recent literature, DHAP offers a powerful approach for the synthesis of efficient active materials, and is a strong substitute for conventional cross-coupling reactions. However, there are still shortcomings that cannot be ignored. For some monomers the reactions are actually controllable with difficulties generating branched, cross-linked polymers and/or by-products due to the activation of more than one $\mathrm{C}-\mathrm{H}$ bond. Additionally, the effects of the steric hindrance of the monomers may have an impact on the polymerization and should also be taken into consideration. Furthermore, it is worth noting that the reaction conditions require specific optimization for each monomer. There are actually, to date, no universal catalytic systems. Under palladium catalysis many parameters including the nature of the additive(s), solvent, ligand(s), reaction temperature and time have a great impact on the conversion. Therefore, the optimum reaction conditions of this non-stationary catalytic system should be achieved by repeated experiments and data analysis. Many questions still remain unanswered and much further work needs to be conducted. Nevertheless, comparisons of materials obtained via DHAP with their analogues prepared via conventional cross-coupling reactions clearly show that DHAP is a method of choice. Indeed, efficient materials prepared using DHAP for polymer solar cells and OFETs have already been reported and this is hopefully just the beginning.

\section{Acknowledgements}

The authors acknowledge financial support from the National Key R\&D Program of "Strategic Advanced Electronic Materials" (No. 2016YFB0401100), the National Natural Science Foundation of China (Grant No. 61574077), and the Natural Science Foundation of Jiangsu (No. SBK2016022423).

\section{Notes and references}

1 J. Hassan, M. Sévignon, C. Gozzi, E. Schulz and M. Lemaire, Chem. Rev., 2002, 102, 1359.

2 A. Suzuki, Chem. Commun., 2005, 4759.

3 C.-J. Li, Chem. Rev., 2005, 105, 3095.

4 P. Morin, T. Bura, B. Sun, S. I. Gorelsky, Y. Li and M. Leclerc, ACS Macro Lett., 2015, 4, 21.

5 M. Poliakoff, J. M. Fitzpatrick, T. R. Farren and P. T. Anastas, Science, 2002, 297, 807.

6 F. Grenier, B. R. Aïch, Y.-Y. Lai, M. Guérette, A. B. Holmes, Y. Tao, W. W. H. Wong and M. Leclerc, Chem. Mater., 2015, 27, 2137.

7 A. E. Rudenko and B. C. Thompson, Macromolecules, 2015, 48, 569.

8 T. Bura, J. T. Blaskovits and M. Leclerc, J. Am. Chem. Soc., 2016, 138, 10056.

9 D. H. Wang, A. Pron, M. Leclerc and A. J. Heeger, Adv. Funct. Mater., 2013, 23, 1297.
10 S.-Y. Liu, W.-Q. Liu, J.-Q. Xu, C.-C. Fan, W.-F. Fu, J. Ling, J.-Y. Wu, M.-M. Shi, A. K. Y. Jen and H.-Z. Chen, ACS Appl. Mater. Interfaces, 2014, 6, 6765.

11 P. D. Homyak, Y. Liu, J. D. Harris, F. Liu, K. R. Carter, T. P. Russell and E. B. Coughlin, Macromolecules, 2016, 49, 3028.

12 A. E. Rudenko, P. P. Khlyabich and B. C. Thompson, ACS Macro Lett., 2014, 3, 387.

13 M. Shaker, C. K. Trinh, W. Kim, H. Kim, K. Lee and J.-S. Lee, New J. Chem., 2015, 39, 4957.

14 S.-W. Chang, H. Waters, J. Kettle and M. Horie, Org. Electron., 2012, 13, 2967.

15 S. Wang, J. Yang, K. Broch, J. Novák, X. Cao, J. Shaw, Y. Tao, Y. Hu and W. Huang, RSC Adv., 2016, 6, 57163.

16 J.-R. Pouliot, B. Sun, M. Leduc, A. Najari, Y. Li and M. Leclerc, Polym. Chem., 2015, 6, 278.

17 P. Sonar, T. R. Foong and A. Dodabalapur, Phys. Chem. Chem. Phys., 2014, 16, 4275.

18 A. D. Hendsbee, J.-P. Sun, L. R. Rutledge, I. G. Hill and G. C. Welch, J. Mater. Chem. A, 2014, 2, 4198.

19 M. K. Poduval, P. M. Burrezo, J. Casado, J. T. López Navarrete, R. P. Ortiz and T.-H. Kim, Macromolecules, 2013, 46, 9220.

20 W. Lu, J. Kuwabara, T. Iijima, H. Higashimura, H. Hayashi and T. Kanbara, Macromolecules, 2012, 45, 4128.

21 M.-L. Sun, W.-S. Zhu, Z.-S. Zhang, C.-J. Ou, L.-H. Xie, Y. Yang, Y. Qian, Y. Zhao and W. Huang, J. Mater. Chem. $C, 2015,3,94$.

22 Y. Zou, A. Najari, P. Berrouard, S. Beaupre, B. Reda Aich, Y. Tao and M. Leclerc, J. Am. Chem. Soc., 2010, 132, 5330.

23 C. Liu, C. Yi, K. Wang, Y. Yang, R. S. Bhatta, M. Tsige, S. Xiao and X. Gong, ACS Appl. Mater. Interfaces, 2015, 7, 4928.

24 J. Zhang, Y. Zhang, J. Fang, K. Lu, Z. Wang, W. Ma and Z. Wei, J. Am. Chem. Soc., 2015, 137, 8176.

25 J. You, L. Dou, K. Yoshimura, T. Kato, K. Ohya, T. Moriarty, K. Emery, C.-C. Chen, J. Gao, G. Li and Y. Yang, Nat. Commun., 2013, 4, 1446.

26 Y. Liu, J. Zhao, Z. Li, C. Mu, W. Ma, H. Hu, K. Jiang, H. Lin, H. Ade and H. Yan, Nat. Commun., 2014, 5, 5293.

27 Z. B. Henson, K. Müllen and G. C. Bazan, Nat. Chem., 2012, 4, 699.

28 E. Iizuka, M. Wakioka and F. Ozawa, Macromolecules, 2015, 48, 2989.

29 M. Wakioka, N. Ichihara, Y. Kitano and F. Ozawa, Macromolecules, 2014, 47, 626.

30 K. Okamoto, J. Zhang, J. B. Housekeeper, S. R. Marder and C. K. Luscombe, Macromolecules, 2013, 46, 8059.

31 J. Kuwabara, T. Yasuda, S. J. Choi, W. Lu, K. Yamazaki, S. Kagaya, L. Han and T. Kanbara, Adv. Funct. Mater., 2014, 24, 3226.

32 N. Allard, A. Najari, J. Pouliot, A. Pron, F. Grenier and M. Leclerc, Polym. Chem., 2012, 3, 2875.

33 N. Allard, S. Beaupre, B. R. Aich, A. Najari, Y. Tao and M. Leclerc, Macromolecules, 2011, 44, 7184.

34 M. Pomerantz, Tetrahedron Lett., 2003, 44, 1563.

35 H. Burckstummer, A. Weissenstein, D. Bialas and F. Wurthner, J. Org. Chem., 2011, 76, 2426. 
36 G. Marzano, D. Kotowski, F. Babudri, R. Musio, A. Pellegrino, S. Luzzati, R. Po and G. M. Farinola, Macromolecules, 2015, 48, 7039.

37 D. Kotowski, S. Luzzati, G. Bianchi, A. Calabrese, A. Pellegrino, R. Po, G. Schimperna and A. Tacca, J. Mater. Chem. A, 2013, 1, 10736.

38 A. E. Rudenko and B. C. Thompson, J. Polym. Sci., Part A: Polym. Chem., 2015, 53, 135.

39 A. E. Rudenko and B. C. Thompson, Macromolecules, 2015, 48, 569.

40 Q. Wang, M. Wakioka and F. Ozawa, Macromol. Rapid Commun., 2012, 33, 1203.

41 A. E. Rudenko, C. A. Wiley, J. F. Tannaci and B. C. Thompson, J. Polym. Sci., Part A: Polym. Chem., 2013, 51, 2660.

42 C. H. Woo, B. C. Thompson, B. J. Kim, M. F. Toney and J. M. J. Frechet, J. Am. Chem. Soc., 2008, 130, 16324.

43 R. D. Mccullough, Adv. Mater., 1998, 2, 93.

44 Q. Wang, R. Takita, Y. Kikuzaki and F. Ozawa, J. Am. Chem. Soc., 2010, 132, 11420.

45 T. Bura, P. O. Morin and M. Leclerc, Macromolecules, 2015, 48, 5614.

46 Q. Guo, J. Dong, D. Wan, D. Wu and J. You, Macromol. Rapid Commun., 2013, 34, 522.

47 A. P. Zoombelt, S. G. J. Mathijssen, M. G. R. Turbiez, M. M. Wienk and R. A. J. Janssen, J. Mater. Chem., 2010, 20, 2240.

48 C. Kanimozhi, N. Yaacobi-Gross, K. W. Chou, A. Amassian, T. D. Anthopoulos and S. Patil, J. Am. Chem. Soc., 2012, 134, 16532.

49 C. Duan, F. Huang and Y. Cao, J. Mater. Chem., 2012, 22, 10416. 50 N. Blouin, A. Michaud, D. Gendron, S. Wakim, E. Blair, R. N. Plesu, M. Belletete, G. Durocher, Y. Tao and M. Leclerc, J. Am. Chem. Soc., 2008, 130, 732.

51 J. Hou, M. Park, S. Zhang, Y. Yao, L. Chen, J. Li and Y. Yang, Macromolecules, 2008, 41, 6012.

52 X. Kang, J. Zhang, D. O'Neil, A. J. Rojas, W. Chen, P. Szymanski, S. R. Marder and M. A. El-Sayed, Chem. Mater., 2014, 26, 4486.

53 X. Wang, K. Wang and M. Wang, Polym. Chem., 2015, 6, 1846.

54 X. Wang, Z.-G. Zhang, H. Luo, S. Chen, S. Yu, H. Wang, X. Li, G. Yu and Y. Li, Polym. Chem., 2014, 5, 502.

55 M. Tomar, A. Z. Ashar, K. S. Narayan, K. Müllen and J. Jacob, J. Polym. Res, 2016, DOI: 10.1007/s10965-016-0945-1.

56 M. Tomar, N. T. Lucas, H. Kim, F. Laquai, K. Müllen and J. Jacob, Polym. Int., 2012, 61, 1318.

57 M. Tomar, N. T. Lucas, M. G. Gardiner, K. Muellen and J. Jacob, Tetrahedron Lett., 2012, 53, 285.

58 C. Piliego, T. W. Holcombe, J. D. Douglas, C. H. Woo, P. M. Beaujuge and J. M. J. Frechet, J. Am. Chem. Soc., 2010, 132, 7595.

59 C. Cabanetos, A. E. Labban, J. A. Bartelt, J. D. Douglas, W. R. Mateker, J. M. J. Frechet, M. D. McGehee and P. M. Beaujuge, J. Am. Chem. Soc., 2013, 135, 4656.

60 G. Zhang, Y. Fu, Q. Zhang and Z. Xie, Chem. Commun., 2010, 46, 4997.
61 X. Guo, N. Zhou, S. J. Lou, J. Smith, D. B. Tice, J. W. Hennek, R. P. Ortiz, J. T. L. Navarrete, S. Li, J. Strzalka, L. X. Chen, R. P. H. Chang, A. Facchetti and T. J. Marks, Nat. Photonics, 2013, 7, 825.

62 K. R. Graham, C. Cabanetos, J. P. Jahnke, N. M. Idso, A. E. Labban, G. O. N. Ndjawa, T. Heumueller, K. Vandewal, A. Salleo, B. F. Chmelka, A. Amassian, P. M. Beaujuge and M. D. McGehee, J. Am. Chem. Soc., 2014, 136, 9608.

63 L. G. Mercier and M. Leclerc, Acc. Chem. Res., 2013, 46, 1597.

64 P. Berrouard, A. Najari, A. Pron, D. Gendron, P. Morin, J. Pouliot, J. Veilleux and M. Leclerc, Angew. Chem., Int. Ed., 2012, 51, 2068.

65 J. Jo, A. Pron, P. Berrouard, W. L. Leong, J. D. Yuen, J. S. Moon, M. Leclerc and A. J. Heeger, Adv. Energy Mater., 2012, 2, 1397.

66 Y. Li and Y. Zou, Adv. Mater., 2008, 20, 2952.

67 F. Lombeck, H. Komber, S. I. Gorelsky and M. Sommer, ACS Macro Lett., 2014, 3, 819.

68 S. Broll, F. Nübling, A. Luzio, D. Lentzas, H. Komber, M. Caironi and M. Sommer, Macromolecules, 2015, 48, 7481.

69 S. Kowalski, S. Allard and U. Scherf, Macromol. Rapid Commun., 2015, 36, 1061.

70 K. Wang, G. Wang and M. Wang, Macromol. Rapid Commun., 2015, 36, 2162.

71 W. Lu, J. Kuwabara and T. Kanbara, Macromolecules, 2011, 44, 1252.

72 Y. Fujinami, J. Kuwabara, W. Lu, H. Hayashi and T. Kanbara, ACS Macro Lett., 2012, 1, 67.

73 L. G. Mercier, B. R. Aïch, A. Najari, S. Beaupré, P. Berrouard, A. Pron, A. Robitaille, Y. Tao and M. Leclerc, Polym. Chem., 2013, 4, 5252.

74 E. Iizuka, M. Wakioka and F. Ozawa, Macromolecules, 2016, 49, 3310.

75 T. Lei, Y. Cao, Y. Fan, C. Liu, S. Yuan and J. Pei, J. Am. Chem. Soc., 2011, 133, 6099.

76 G. Zhang, Y. Fu, Z. Xie and Q. Zhang, Macromolecules, 2011, 44, 1414.

77 R. Stalder, J. Mei and J. R. Reynolds, Macromolecules, 2010, 43, 8348.

78 R. Stalder, J. Mei, J. Subbiah, C. Grand, L. A. Estrada, F. So and J. R. Reynolds, Macromolecules, 2011, 44, 6303.

79 Z. Ma, E. Wang, M. E. Jarvid, P. Henriksson, O. Inganas, F. Zhang and M. R. Andersson, J. Mater. Chem., 2012, 22, 2306.

80 K. Mahmood, Z.-P. Liu, C. Li, Z. Lu, T. Fang, X. Liu, J. Zhou, T. Lei, J. Pei and Z. Bo, Polym. Chem., 2013, 4, 3563.

81 P. Sonar, H.-S. Tan, S. Sun, Y. M. Lam and A. Dodabalapur, Polym. Chem., 2013, 4, 1983.

82 Y. Deng, J. Liu, J. Wang, L. Liu, W. Li, H. Tian, X. Zhang, Z. Xie, Y. Geng and F. Wang, Adv. Mater., 2014, 26, 471.

83 L. Fang, Y. Zhou, Y.-X. Yao, Y. Diao, W.-Y. Lee, A. L. Appleton, R. Allen, J. Reinspach, S. C. B. Mannsfeld and Z. Bao, Chem. Mater., 2013, 25, 4874.

84 Z. Ma, D. Dang, Z. Tang, D. Gedefaw, J. Bergqvist, W. Zhu, W. Mammo, M. R. Andersson, O. Inganäs, F. Zhang and E. Wang, Adv. Energy Mater., 2014, 4, 1301455. 
85 T. Lei, J.-H. Dou, Z.-J. Ma, C.-H. Yao, C.-J. Liu, J.-Y. Wang and J. Pei, J. Am. Chem. Soc., 2012, 134, 20025.

86 J. Mei, D. H. Kim, A. L. Ayzner, M. F. Toney and Z. Bao, J. Am. Chem. Soc., 2011, 133, 20130.

87 T. Lei, J.-H. Dou and J. Pei, Adv. Mater., 2012, 24, 6457.

88 F. Grenier, P. Berrouard, J. Pouliot, H.-R. Tseng, A. J. Heeger and M. Leclerc, Polym. Chem., 2013, 4, 1836.

89 M. C. Scharber, D. Mühlbacher, M. Koppe, P. Denk, C. Waldauf, A. J. Heeger and C. J. Brabec, Adv. Mater., 2006, 18, 789.

90 T. Lei, Y. Cao, X. Zhou, Y. Peng, J. Bian and J. Pei, Chem. Mater., 2012, 24, 1762.

91 E. von Hauff, V. Dyakonov and J. Parisi, Sol. Energy Mater. Sol. Cells, 2005, 87, 149.

92 C. Waldauf, P. Schilinsky, M. Perisutti, J. Hauch and C. J. Brabec, Adv. Mater., 2003, 15, 2084.

93 W. Elsawy, H. Kang, K. Yu, A. Elbarbary, K. Lee and J.-S. Lee, J. Polym. Sci., Part A: Polym. Chem., 2014, 52, 2926.

94 D. Gebeyehua, C. J. Brabeca, F. Padingerb, T. Fromherzb, J. C. Hummelenc, D. Badtd, H. Schindlerd and N. S. Sariciftcia, Synth. Met., 2001, 118, 1.

95 K. Geyer, J. D. C. Codée and P. H. Seeberger, Chem. - Eur. J., 2006, 12, 8434.

96 G. Jas and A. Kirschning, Chem. - Eur. J., 2003, 9, 5708.

97 Y. S. Kwon, J. Lim, H. Yun, Y. Kim and T. Park, Energy Environ. Sci., 2014, 7, 1454.

98 J. W. Jung, F. Liu, T. P. Russell and W. H. Jo, Energy Environ. Sci., 2012, 5, 6857.

99 W. Li, W. S. C. Roelofs, M. Turbiez, M. M. Wienk and R. A. J. Janssen, Adv. Mater., 2014, 26, 3304.

100 L. Dou, J. You, J. Yang, C.-C. Chen, Y. He, S. Murase, T. Moriarty, K. Emery, G. Li and Y. Yang, Nat. Photonics, 2012, 6, 180.

101 W. Li, A. Furlan, K. H. Hendriks, M. M. Wienk and R. A. J. Janssen, J. Am. Chem. Soc., 2013, 135, 5529.

102 K. H. Hendriks, G. H. L. Heintges, V. S. Gevaerts, M. M. Wienk and R. A. J. Janssen, Angew. Chem., Int. Ed., 2013, 52, 8341.

103 J. Kuwabara, Y. Nohara, S. J. Choi, Y. Fujinami, W. Lu, K. Yoshimura, J. Oguma, K. Suenobu and T. Kanbara, Polym. Chem., 2013, 4, 947.

104 H. Zhou, L. Yang and W. You, Macromolecules, 2012, 45, 607.
105 H. Zhou, L. Yang, S. Xiao, S. Liu and W. You, Macromolecules, 2010, 43, 811.

106 Q. Shi, H. Fan, Y. Liu, J. Chen, L. Ma, W. Hu, Z. Shuai, Y. Li and X. Zhan, Macromolecules, 2011, 44, 4230.

107 Y.-J. Cheng, S.-H. Yang and C.-S. Hsu, Chem. Rev., 2009, 109, 5868.

108 P. T. Boudreault, A. Najari and M. Leclerc, Chem. Mater., 2011, 23, 456.

109 A. Facchetti, Chem. Mater., 2011, 23, 733.

110 S.-W. Chang, H. Waters, J. Kettle, Z.-R. Kuo, C.-H. Li, C.-Y. Yu and M. Horie, Macromol. Rapid Commun., 2012, 33, 1927.

111 Y. Zou, D. Gendron, R. Neagu-Plesu and M. Leclerc, Macromolecules, 2009, 42, 6361.

112 E. Zhou, S. Yamakawa, K. Tajima, C. Yang and K. Hashimoto, Chem. Mater., 2009, 21, 4055.

113 S. Cho, J. Lee, M. Tong, J. H. Seo and C. Yang, Adv. Funct. Mater., 2011, 21, 1910.

114 S. Qu and H. Tian, Chem. Commun., 2012, 48, 3039.

115 Y. Li, S. P. Singh and P. Sonar, Adv. Mater., 2010, 22, 4862.

116 L. Dou, W.-H. Chang, J. Gao, C.-C. Chen, J. You and Y. Yang, Adv. Mater., 2013, 25, 825.

117 P. Homyak, Y. Liu, F. Liu, T. P. Russel and E. B. Coughlin, Macromolecules, 2015, 48, 6978.

118 Z. Yi, S. Wang and Y. Liu, Adv. Mater., 2015, 27, 3589.

119 J. Kuwabara, K. Yamazaki, T. Yamagata, W. Tsuchida and T. Kanbara, Polym. Chem., 2015, 6, 891.

120 A. E. Rudenko, C. A. Wiley, S. M. Stone, J. F. Tannaci and B. C. Thompson, J. Polym. Sci., Part A: Polym. Chem., 2012, 50, 3691.

121 A. E. Rudenko and B. C. Thompson, J. Polym. Sci., Part A: Polym. Chem., 2015, 53, 135.

122 Y. Gao, X. Zhang, H. Tian, J. Zhang, D. Yan, Y. Geng and F. Wang, Adv. Mater., 2015, 27, 6753.

123 J. Lee, A. Han, J. Kim, Y. Kim, J. H. Oh and C. Yang, J. Am. Chem. Soc., 2012, 134, 20713.

124 I. Kang, H.-J. Yun, D. S. Chung, S.-K. Kwon and Y.-H. Kim, J. Am. Chem. Soc., 2013, 135, 14896.

125 B. Sun, W. Hong, Z. Yan, H. Aziz and Y. Li, Adv. Mater., 2014, 26, 2636.

126 K.-H. Kim, S. Park, H. Yu, H. Kang, I. Song, J. H. Oh and B. J. Kim, Chem. Mater., 2014, 26, 6963.

127 H.-J. Yun, S.-J. Kang, Y. Xu, S. O. Kim, Y.-H. Kim, Y.-Y. Noh and S.-K. Kwon, Adv. Mater., 2014, 26, 7300. 